\title{
An Ocular Form of Myasthenia Gravis with a High Titer of Anti-MuSK Antibodies during a Long-term Follow-up
}

\author{
Ai Hosaka ${ }^{1}$, Hiroshi Takuma ${ }^{1}$, Kiyoe Ohta $^{2}$ and Akira Tamaoka ${ }^{1}$
}

\begin{abstract}
We herein report a case of ocular myasthenia gravis (MG) that was highly positive for anti-muscle-specific tyrosine kinase (MuSK) antibodies. The examined patient exhibited bilateral ptosis and lateral gaze palsy without any generalized symptoms and was diagnosed with ocular MG with anti-MuSK antibodies. She responded to treatment with prednisolone and immunosuppressants and experienced only ocular symptoms for four years and eight months after onset. Ocular MG with anti-MuSK antibodies lasting for a long term has rarely been described. Our findings suggest that it may be reasonable to test for the presence of anti-MuSK antibodies in patients who present with external ophthalmoplegia.
\end{abstract}

Key words: myasthenia gravis, ocular form, anti-MuSK antibodies, autoimmune disease, long-term

(Intern Med 51: 3077-3079, 2012)

(DOI: 10.2169/internalmedicine.51.8196)

\section{Introduction}

The autoimmune mechanism of myasthenia gravis (MG) was established in 1976 (1). It has been found that $85 \%$ of MG patients are positive for anti-acetylcholine receptor (AChR) antibodies (AChR-MG), and up to $50 \%$ of patients with ocular MG have detectable levels of anti-AChR antibodies (2). Recently, antibodies against muscle-specific tyrosine kinase (MuSK) were reported to be present in $38-70 \%$ of patients with seronegative generalized MG (3-5). AntiMuSK antibody-positive MG (MuSK-MG) tends to be more severe and more focused in the facio-bulbar area than AChR-MG. The present report describes a case of "ocular" MG and anti-MuSK antibodies lasting over four and a half years.

\section{Case Report}

A 33-year-old, right-handed woman developed intermittent diplopia. She was examined by an ophthalmologist; however, no restrictions of eye movement or any other symptoms were revealed. MRI of the brain showed no abnormalities. Two weeks later, the patient's symptoms sponta- neously improved. After the diplopia repeated two, seven and 19 months later, she was evaluated by a neurologist and was thereafter admitted to our hospital. A neurological examination revealed bilateral ptosis with fatigability and fluctuations over the course of a day. The patient had subjective diplopia, and her extraocular movements presented as lateral gaze palsy. She had no facial or jaw weakness, and she had full strength throughout the neck and limbs. However, because detecting weakness in the orbicularis oculi muscle is difficult, the presence of undetectable weakness cannot be excluded. The patient's deep tendon reflexes and sensation were normal. Thyroid function, the erythrocyte sedimentation rate, tests for rheumatoid factor and the creatine kinase levels were normal. An anti-nuclear antibody titer was negative. An anti-AChR antibody titer was within the normal range. The anti-MuSK antibody titer was determined using radioimmunoassay and the concentration measured 106.0 $\mathrm{nM}$, clearly higher than the cutoff value $(0.01 \mathrm{nM})(6)$. Repetitive nerve stimulation at $5 \mathrm{~Hz}$ revealed a $27 \%$ decrement of the left orbicularis oculi; however, the test did not show any decrease in the deltoid muscle. The patient was diagnosed to have ocular form-MG with anti-MuSK antibodies. The administration of i.v. edorophonium was positive for repetitive nerve stimulation and the symptoms of diplopia. A

${ }^{1}$ Department of Neurology, Faculty of Medicine, University of Tsukuba, Japan and ${ }^{2}$ Clinical Research Center, National Hospital Organization Utano National Hospital, Japan

Received for publication May 20, 2012; Accepted for publication July 30, 2012

Correspondence to Dr. Hiroshi Takuma, htakuma@md.tsukuba.ac.jp 
Table. Summary of Cases with Ocular MG and Anti-MuSK Antibodies

\begin{tabular}{|c|c|c|c|c|c|}
\hline & Caress, 2005 & Bennett, 2006 & Hanisch, 2006 & Chan, 2007 & our case \\
\hline Age (at onset) & 18 & 21 & 55 & 37 & 33 \\
\hline Gender & $\mathrm{F}$ & $\mathrm{F}$ & $\mathrm{F}$ & M & $\mathrm{F}$ \\
\hline disease duration & $?$ & $?$ & 3.7 years & 14.5 years & 4.7 years \\
\hline edrophonium test & not examined & negative & negative & not examined & positive \\
\hline titer of anti-MuSK antibodies & $31,435 \mathrm{pg} / \mathrm{mL}$ & positive & $1: 13$ & $32,693 \mathrm{pg} / \mathrm{mL}$ & $106.0 \mathrm{nM}$ \\
\hline piridostigmine & stopped by side effect & not effective & used & used & effective \\
\hline prednisolone (initial) & $40 \mathrm{mg} /$ day & $10 \mathrm{mg} /$ day & not used & used & $30 \mathrm{mg} /$ day \\
\hline immunosuppressant & not used & & azatioprine & not used & tacrolimus \\
\hline thymectomy & not done & not done & not done & done & not done \\
\hline others & & & & ocular muscle atrophy & \\
\hline
\end{tabular}

CT scan of the patient's chest with contrast enhancement revealed a normal thymus gland without thymoma. The forced vital capacity was $110 \%$ and the quantitative myasthenia gravis (QMG) score was 6 with spontaneous double vision and ptosis.

First, the patient was given $120 \mathrm{mg}$ of pyridostigmine/day and $1 \mathrm{mg}$ of atropine/day. This medication proved to be effective for the diplopia; however, the patient was unable to continue taking the medicine due to fasciculation of the facial muscles and diarrhea. Then, at two years from the onset of the disease, the patient was started on prednisolone at a dose of $5 \mathrm{mg} /$ day p.o. that was gradually increased. One month later, the dose was increased to $30 \mathrm{mg} / \mathrm{day}$, and a complete improvement was observed in the diplopia and ptosis. After four weeks of $30 \mathrm{mg}$ of daily prednisolone, the dose was gradually tapered down to $12.5 \mathrm{mg}$ /day; however, the diplopia became slightly recurrent, and after three years from the onset of symptoms, $3 \mathrm{mg}$ of daily tacrolimus was added. Following this, the patient's diplopia and ptosis were under good control without any exacerbation, and the titer of anti-MuSK antibodies decreased to $47.0 \mathrm{nM}$. The dose of prednisolone was then decreased to $5 \mathrm{mg}$ daily. The patient underwent careful neurological examinations and an electrophysiological test after four and a half years from the onset of symptoms. She showed no generalization. Her symptoms were under good control without the occurrence of myasthenia or ocular symptoms after four years and eight months from the onset of the disease.

\section{Discussion}

We herein report a rare case involving purely ocular symptoms that was positive for anti-MuSK antibodies over a long-term follow-up period. Approximately $80-90 \%$ of patients with MG are positive for anti-AChR antibodies, and $39-49 \%$ of Italian and American (7) and $27 \%$ of Japanese (6) seronegative patients have antibodies against MuSK.

Recently, Guptill et al. reported that $39 \%$ of 110 MuSK patients had only ocular symptoms at onset, although none exhibited only purely ocular symptoms throughout their clinical course (7). The patients usually progressed to generalized disease within two to three weeks; however, in some patients, fluctuating ptosis and diplopia remained the only complaint for up to 48 months before bulbar and/or neck weakness occurred. Only four cases of MuSK-MG involving ocular muscles have been reported (Table) (8-11). Two of these involved observation for short terms of less than three to four months $(8,9)$ and had the potential for generalization later. The other two cases involved observation for longer terms $(10,11)$. Hanisch et al. reported a patient with only ocular symptoms who was diagnosed with MuSK-MG two years after onset and showed only ocular symptoms for 20 months after the initiation of treatment with azathioprine and pyridostigmine (10). Chan et al. reported a patient with only ocular symptoms who was diagnosed 12 years after onset (11). In that case, ocular MRI revealed ocular muscle atrophy. The patient showed ocular symptoms for two and half years after treatment with thymectomy, prednisolone and pyridostigmine. The latter case involved an approximately 15-year duration of limited ocular motility that did not improve with medication or thymectomy. In that case, other diseases were not adequately excluded. Our patient continued to have ocular symptoms without progression to generalization for more than four and a half years. MuSKMG with only ocular symptoms occurring over a long term is very rare. In our case, treatment with immunosuppressants, such as prednisolone and tacrolimus, and pyridostigmine was able to prevent progression.

Disease severity and the antibody level are strongly correlated in patients with MuSK-MG (6). Although, in our case, the titer of serum anti-MuSK antibodies decreased under corticosteroid therapy, corresponding with an improvement in the patient's symptoms, the initial titer of anti-MuSK antibodies was extremely high, similar to that observed in the other ocular cases $(8,9)$.

MuSK-MG has been suggested to have three clinical presentations: indistinguishable from generalized AChR-MG, severe oculobulbar weakness and weakness of the neck, shoulders and respiratory muscles with delayed ocular involvement (3). Our patient might therefore be at risk for developing a subsequent generalization of MG and should therefore be carefully observed in the future because there is no adequate evidence to indicate that immunosuppressive therapy reduces the probability of a progression to generalized MG (12). Although ocular involvement is a rare presentation 
of MuSK-MG, it may be reasonable to examine individuals for the presence of anti-MuSK antibodies in any patient who presents with external ophthalmoplegia. Early treatment and care may therefore prevent the risk of a sudden worsening of critical symptoms.

The authors state that they have no Conflict of Interest (COI).

\section{Acknowledgement}

We thank Dr. Hiromi Maekawa of Osaka University for her helpful comments and Dr. Tetsuto Yamaguchi for his valuable discussions.

\section{References}

1. Lindstrom JM, Seybold ME, Lennon VA, Whittingham S, Duane DD. Antibody to acetylcholine receptor in myasthenia gravis. Prevalence, clinical correlates, and diagnostic value. Neurology 26: 1054-1059, 1976.

2. Meriggioli MN, Sanders DB. Autoimmune myasthenia gravis: emerging clinical and biological heterogeneity. Lancet Neurol 8: 475-490, 2009

3. McConville J, Farrugia ME, Beeson D, et al. Detection and characterization of MuSK antibodies in seronegative myasthenia gravis. Ann Neurol 55: 580-584, 2004.

4. Sanders DB, El-Salem K, Massey JM, McConville J, Vincent A.
Clinical aspects of MuSK antibody positive seronegative MG. Neurology 60: 1978-1980, 2003.

5. Hoch W, McConville J, Helms S, Newsom-Davis J, Melms A, Vincent A. Auto-antibodies to the receptor tyrosine kinase MuSK in patients with myasthenia gravis without acetylcholine receptor antibodies. Nat Med 7: 365-368, 2001.

6. Ohta K, Shigemoto K, Fujinami A, Maruyama N, Konishi T, Ohta M. Clinical and experimental features of MuSK antibody positive MG in Japan. Eur J Neurol 14: 1029-1034, 2007.

7. Guptill JT, Sanders DB, Evoli A. Anti-MuSK antibody myasthenia gravis: clinical findings and response to treatment in two large cohorts. Muscle Nerve 44: 36-40, 2011.

8. Caress JB, Hunt CH, Batish SD. Anti-MuSK myasthenia gravis presenting with purely ocular findings. Arch Neurol 62: 10021003, 2005.

9. Bennett DL, Mills KR, Riordan-Eva P, Barnes PR, Rose MR. Anti-MuSK antibodies in a case of ocular myasthenia gravis. $\mathrm{J}$ Neurol Neurosurg Psychiatry 77: 564-565, 2006.

10. Hanisch F, Eger K, Zierz S. MuSK-antibody positive pure ocular myasthenia gravis. J Neurol 253: 659-660, 2006.

11. Chan JW, Orrison WW. Ocular myasthenia: a rare presentation with MuSK antibody and bilateral extraocular muscle atrophy. $\mathrm{Br}$ J Ophthalmol 91: 842-843, 2007.

12. Benatar M, Kaminski HJ. Evidence report: the medical treatment of ocular myasthenia (an evidence-based review): report of the Quality Standards Subcommittee of the American Academy of Neurology. Neurology 68: 2144-2149, 2007.

(C) 2012 The Japanese Society of Internal Medicine http://www.naika.or.jp/imonline/index.html 